\title{
The effect of $D$-amphetamine on energy balance in hypothalamic obese rats
}

\author{
BY G. C. KENNEDY AND J. MITRA \\ Medical Research Council Department of Experimental Medicine, University of \\ Cambridge
}

(Received 8 March 1963-Revised 30 May 1963)

A number of stimulants of the central nervous system are used to treat obesity because they are believed to inhibit appetite. The anorexic effect is difficult to demonstrate unequivocally in man; Wilson \& Schild (1959), for example, say of D-amphetamine, the best-known drug of this group, that its chief value is to make it less unpleasant for the co-operative patient to deny himself food. Nevertheless, it is well established that amphetamine can cause weight losses in both man and animals (Harris, Ivy \& Searle, 1947; Williams, Daughaday, Rogers, Asper \& Beverly, 1948; Adlersberg \& Mayer, 1949). The possibility exists that the stimulant effect of the drugs may contribute to such weight loss, for spontaneous locomotor activity is an important factor in determining energy balance (Mayer, 1955) and is regulated to a great extent by the same hypothalamic region that governs appetite (Kennedy, I96I; Kennedy \& Mitra, 1963). The object of the work described in this paper was to find out how lesions in the hypothalamus of rats affected both the stimulant and the anorexic action of amphetamine.

\section{EXPERIMENTAL}

We used thirty-five young female rats of the Lister hooded strain, ten normal and twenty-five made hyperphagic by placing bilateral electrolytic lesions in the lateral part of the ventromedial nuclei of the hypothalamus. All the control animals and seven of the operated ones were housed in activity-measuring cages of the treadmill variety; the remainder of the operated rats were kept in ordinary cages. The techniques of operation and activity measurement have been fully described (Kennedy \& Mitra, 1963). The experiments took place in an air-conditioned room between 75 and $80^{\circ} \mathrm{F}$ with lighting from 6 a.m. to 6 p.m. The diet was the powdered MRC diet 41 B (Bruce, 1958), of which a weighed amount was given daily, moistened with an equal weight of water, any rejected food being dried before reweighing. D-amphetamine sulphate was given when appropriate, mixed with the diet in the proportion of $0.0625 \mathrm{mg} / \mathrm{g} \mathrm{dry}$ diet. With an approximate daily intake of $15^{-20} \mathrm{~g}$, a normal female rat weighing $250 \mathrm{~g}$ thus received $4-5 \mathrm{mg} / \mathrm{kg}$ body-weight daily.

After hypothalamic operation all rats were given normal food ad lib. for at least 5 days and their hyperphagia was graded as 'severe' if they ate more than $40 \mathrm{~g} /$ day and as 'moderate' if they ate less (Fig. I). Their intake was then restricted until they regained their pre-operative weight, after which sufficient food was given to maintain weight gain at the slow rate seen before operation; the amount varied from day to day and from animal to animal and was found by trial and error. The effects of amphetamine 
were studied in three ways. First, the effect on running activity alone was tested by changing to the diet containing amphetamine while maintaining the slow gain in weight (point $A$ in Fig. x $a, b$ ). Next, the amphetamine diet was given ad lib. (point $B$ ); after 3 or 4 days, during which a uniform daily intake became established, food intake and activity were measured for 5 days. Normal diet was substituted for comparison (point $C$ ); after a steady level of intake was reached, intake and

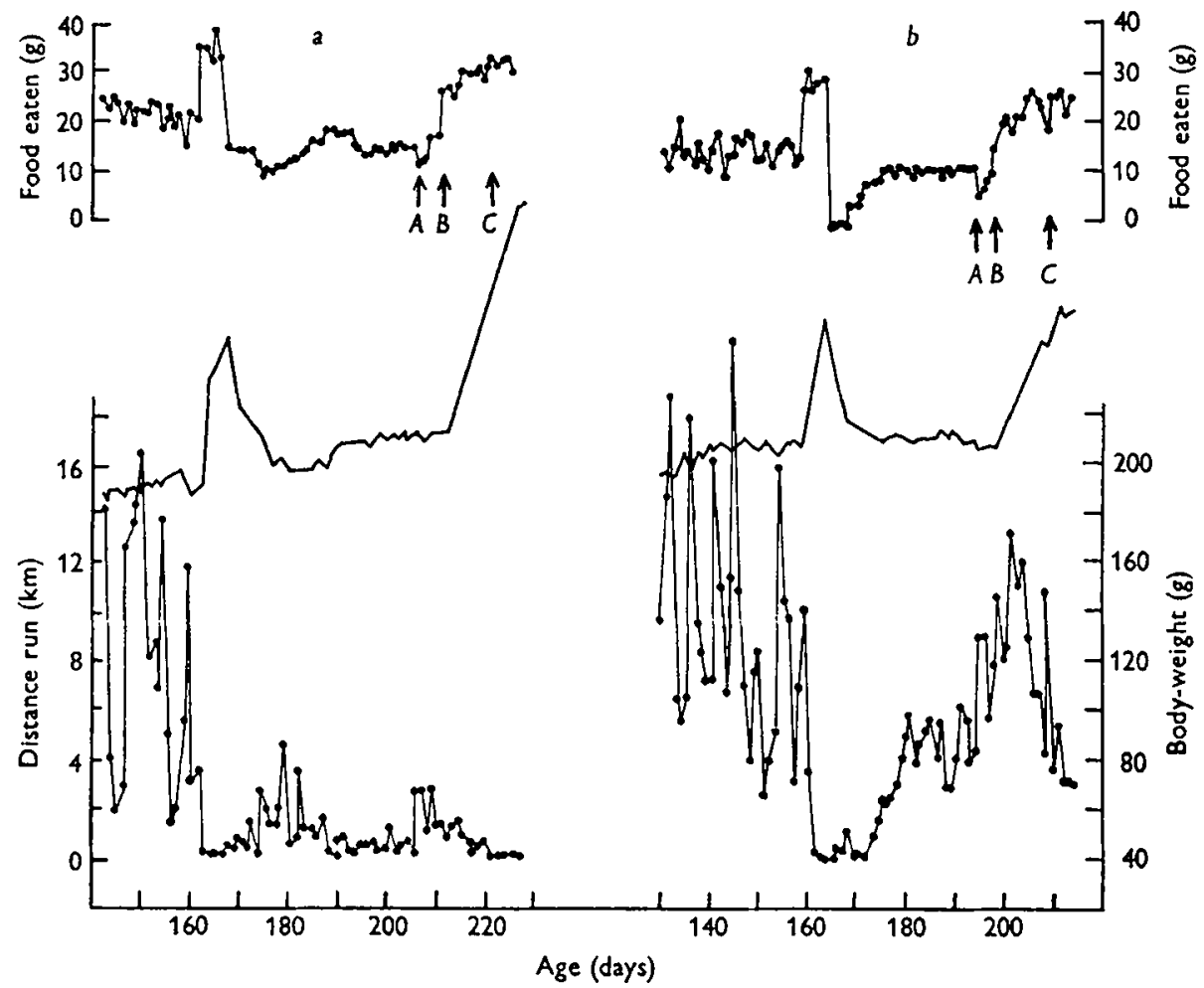

Fig. I. (a) Daily food intake (upper curve), body-weight (middle curve) and running activity (lower curve) of a female rat subjected to hypothalamic operation when $16 \mathrm{r}$ days old. Up to point $A$ and after point $C$ stock diet was given; between $A$ and $B$ the diet containing Damphetamine sulphate was given in restricted amounts and between $B$ and $C$ it was given ad lib. (b) Similar results from a less hyperphagic rat, operated upon when 157 days old. Running activity in this animal was restored to the pre-operative level by food restriction together with amphetamine.

activity were recorded for a further 5 days. Finally, the rats were allowed to eat freely for 3 months, during which time a steady level of obesity developed, and the intakes of the normal diet and the amphetamine diet were again compared for 5-day periods. Since activity in female rats is greatly influenced by the oestrous cycle, daily vaginal smears were taken from all rats in activity cages.

In ordinary cages the preliminary comparison at constant body-weight was omitted, but ad lib. intakes with and without amphetamine were compared during hyperphagia and in established obesity. The order in which the diets were given was varied.

In unoperated rats only a single comparison of the normal with the amphetamine diet was made with each animal. 


\section{RESULTS}

Food intake. Table I shows for normal, moderately hyperphagic and severely hyperphagic rats the percentage depressions of intake caused by amphetamine. There was no difference in response between normal and moderately hyperphagic animals, but severely hyperphagic ones were much less affected although, since they ate twice as much, they received twice as much of the drug $(t=3.65, \mathrm{df}=23, P<0.01)$.

A much greater effect was seen in established obesity, as shown in the last two lines of Table $\mathrm{r}$. The mean intake of normal diet by obese rats was $25 \mathrm{~g} /$ day, only a little higher than that of control animals, so that the initial dose of amphetamine received by each group was of the same order. Nevertheless, the obese rats reduced their intake more than the controls did; since the severity of the obesity made little difference to the response, all the surviving rats were grouped together. In an attempt to compare their sensitivity to amphetamine with that in the hyperphagic period, its concentration in the diet of the obese animals was doubled, and the responses are recorded in the last line of the table. The comparison still underestimates the increase in sensitivity because of the low intake of the obese rats.

Table I. Mean values with standard deviations for percentage fall in food intake caused by $D$-amphetamine in normal rats and in rats with hypothalamic lesions

$\begin{array}{lcc}\quad \text { State of rats } & \begin{array}{c}\text { No. of } \\ \text { rats }\end{array} & \text { Fall in intake } \\ \begin{array}{l}\text { Normal } \\ \text { Hyperphagic } \\ \quad \text { Moderately }\end{array} & 10 & 21 \cdot 8 \pm 10 \cdot 7 \\ \quad \text { Severely } & \text { 10 } & 22 \cdot 2 \pm 13 \cdot 0 \\ \begin{array}{l}\text { Obese } \\ \quad \text { Given single dose }\end{array} & 15 & 6 \cdot 1 \pm 11 \cdot 1 \\ \quad \text { Given double dose } & 23 & 31 \cdot 4 \pm 14 \cdot 5 \\ & 23 & 56 \cdot 1 \pm 21\end{array}$

Running activity. Fig. I $a$ shows the food intake, body-weight and running activity of a hyperphagic rat. Hypothalamic operation led to an immediate rise in food intake and body-weight and a fall in activity to nearly nil. There was a partial return of activity during underfeeding, but when the body-weight stabilized activity fell again. When amphetamine was introduced into the diet without allowing the weight to rise, the animal ran less than when underfed. When the amphetamine diet was given freely, the intake of both food and drug doubled; activity fell again. Finally, the normal diet was given ad lib. and there was a little further increase in intake and fall in activity. This rat was on the dividing line between severe and moderate hyperphagia, as defined earlier. Animals that ate more were even less sensitive to arousal by amphetamine, just as they had previously been shown to run less during starvation (Kennedy, 196r). Rats less hyperphagic could be restored to normal activity by a combination of food restriction and amphetamine, but by neither alone (Fig. $1 b$ ).

When obesity was fully established, activity always fell to a low level, and we found no stimulating effect from amphetamine. 


\section{DISCUSSION}

Stowe \& Miller (1957) showed that bilateral ablation of the ventromedial nuclei in rats enhanced rather than abolished the inhibition of appetite by amphetamine; they concluded that, since the drug did not work on the ventromedial satiety mechanism, it must work on the lateral hypothalamic 'feeding centre' (Anand \& Brobeck, 195I). Neither conclusion seems justified. First, the ablated centre may well play a part in mediating the action of amphetamine in the intact animal, and failure of ablation to abolish the effect merely shows that other centres are also involved. Secondly, neither our experiments nor those of Stowe \& Miller throw any light on where these other centres are, for appetite regulation involves a much more extensive central nervous hierarchy than the two hypothalamic regions mentioned (Brobeck, 1960; Anand, 196r). Moreover, although we agree that the removal of the ventromedial nuclei does not abolish the anorexic effect of amphetamine, it greatly alters it. In fully established obesity, we confirmed that the effect was enhanced, but during the hyperphagia that preceded the obesity amphetamine had a greatly reduced effect. Such facilitation of appetite inhibition by adiposity has been reported in a variety of circumstances (Kennedy, 1952-3; Teitelbaum, 1955); its mechanism is unknown. Its practical significance seems clear, however, for if, as is often assumed, clinical obesity involves dysfunction of the ventromedial centres, such dysfunction would be no bar to the use of amphetamine.

Our findings about activity were unequivocal; the ventromedial nuclei were essential to the stimulant effect of the drug although, as we had previously found with underfeeding, it was only in the most potentially severe obesity that no activity at all was provoked. Brobeck, Larsson \& Reyes (1956) recorded electrical activity from various parts of the hypothalamus of cats and found that amphetamine stimulated the ventromedial region. An association between electrical and behavioural arousal by amphetamine has been observed in experiments on the reticular formation by Bradley (1957), and it seems likely that a similar association might exist at the hypothalamic level. There is no way of checking experimental findings such as this in man, but the hypothalamic control of food intake is remarkably similar in all the mammals that have been studied. If it is permissible to reason from rats to man, the practical inference seems to be that little can be hoped for therapeutically in obese subjects from stimulation of activity by such drugs; in view of the danger of loss of sleep, it is probably more rational to use one of the newer compounds that are claimed to be less stimulating.

\section{SUMMARY}

I. Young female rats housed in activity-measuring cages were made hyperphagic by placing bilateral lesions in the ventromedial nuclei of the hypothalamus; besides increased food intake, all of them showed reduced locomotor activity.

2. Running could not be stimulated in severely hyperphagic rats by giving Damphetamine sulphate, although restoration of about half the pre-operative activity occurred in milder hyperphagia. 
3. Food consumption was less affected by amphetamine in hyperphagic rats than in normal ones, but the same operated rats became abnormally sensitive to the anorexic action after they became obese. By contrast they were even less active, with or without amphetamine, when obese than when hyperphagic.

4. It is concluded that the ventromedial nucleus is essential to the general stimulant action of the drug, but not to its anorexic effect.

\section{REFERENCES}

Adlersberg, D. \& Mayer, M. E. (1949). Y. clin. Endocrin. 9, 275.

Anand, B. K. (1961). Physiol. Rev. 41,677.

Anand, B. K. \& Brobeck, J. R. (195I). Yale Y. Biol. Med. 24, 123.

Bradley, P. B. (1957). In The Reticular Formation of the Brain Stem: Anatomical Aspects and Functional Correlations. [A. Brodal, editor.] London: Churchill.

Brobeck, J. R. (1960). In Handbook of Physiology. Vol, 2, Neurophysiology, p. 1 197. [J. Field, editor.] Washington, D.C.: American Physiological Society.

Brobeck, J. R., Larsson, S. \& Reyes, E. (1956). F. Physiol. r32, 358.

Bruce, H. M. (1958). Stud. Fertil. 9, 90 .

Harris, S. C., Ivy, A. C. \& Searle, L. M. (1947). Y. Amer. med. Ass. 134, 1468.

Kennedy, G. C. (1952-3). Proc. roy. Soc. B, 140, 578.

Kennedy, G. C. (1961). Proc. Nutr. Soc. 20, 58.

Kennedy, G. C. \& Mitra, J. (I963). F. Physiol. I66, 395.

Mayer, J. (1955). Ann. N.Y. Acad. Sci. 63, 15.

Stowe, F. R. Jr. \& Miller, A. T. Jr. (1957). Experientia, 13, I 44.

Teitelbaum, P. (1955). Y. comp. Physiol. Psychol. 48, 156.

Williams, R. H., Daughaday, W. H., Rogers, W. F. Jr., Asper, S. P. Jr. \& Beverly, T. T. (1948). Ann. intern. Med. 29, 5 10.

Wilson, A. \& Schild, H. O. (editors) (1959). Clark's Applied Pharmacology, gth ed. London: Churchill. 